\title{
Obesity Is Associated with an Increase in Pharmaceutical Expenses among University Employees
}

\author{
Julie A. Gazmararian, ${ }^{1}$ David Frisvold, ${ }^{2}$ Kun Zhang, ${ }^{3}$ and Jeffrey P. Koplan ${ }^{4}$ \\ ${ }^{1}$ Department of Epidemiology, Rollins School of Public Health, Emory University, Atlanta, GA 30322, USA \\ ${ }^{2}$ Department of Economics, University of Iowa, Iowa City, IA 52242, USA \\ ${ }^{3}$ Department of Health Policy and Management, Rollins School of Public Health, Emory University, \\ Atlanta, GA 30322, USA \\ ${ }^{4}$ Emory Global Health Institute, Emory University, Atlanta, GA 30322, USA
}

Correspondence should be addressed to Julie A. Gazmararian; jagazma@sph.emory.edu

Received 27 September 2014; Accepted 16 January 2015

Academic Editor: Francesco Saverio Papadia

Copyright (C) 2015 Julie A. Gazmararian et al. This is an open access article distributed under the Creative Commons Attribution License, which permits unrestricted use, distribution, and reproduction in any medium, provided the original work is properly cited.

\begin{abstract}
Objective. To examine costs associated with obesity in an employee population and factors associated with increased costs. Methods. We used data from the Physical Activity and Life Style (PALS) study, a randomized prospective design evaluating three interventions to increase physical activity among physically inactive nonfaculty university employees $(n=454)$. The primary exposure variable, obesity (measured by body mass index), was obtained from the in-person baseline survey. Covariates were obtained from the baseline survey and included demographic characteristics and health status. Data from the baseline survey was linked with administrative data to determine pharmaceutical, inpatient, outpatient, and total health care costs for three years. Average monthly expenditures for obese and nonobese individuals were compared using $t$-tests and a two-part multivariate regression model adjusted for demographic and socioeconomic characteristics and health behaviors. Results. Although in-patient and outpatient expenses were not associated with obesity, pharmaceutical expenditures were $\$ 408$ or $87.2 \%$ higher per year ( $\$ 468$ versus $\$ 876$ ) for obese individuals than for nonobese individuals, which reflected poorer health behaviors and health status of obese adults. Conclusion. Awareness of the costs associated with obesity among employees can stimulate employers to make the investment in providing employer-sponsored wellness and health improvement programs to address obesity.
\end{abstract}

\section{Introduction}

In the United States, obesity among adults has increased markedly since 1980 [1]. In 2011-2012, 34.9\% of adults $20-74$ years old were obese [2]. A higher body weight is associated with an increased incidence of a number of health conditions, including diabetes mellitus, cardiovascular disease, and nonalcoholic fatty liver disease, and with an increased risk of disability [3]. Obesity is associated with a modestly increased risk of all-cause mortality $[4,5]$.

The social and economic costs of obesity are high [2]. Overweight and obesity attributable medical spending/expenditures accounted for $9.1 \%$ of total annual US medical expenditures or $\$ 78.5$ billion in 1998 [6]. Increases in the proportion of and spending on obese people relative to people of normal weight account for $27 \%$ of the rise in inflationadjusted per capita health care spending between 1987 and 2001. Increases in obesity prevalence alone account for $12 \%$ of the growth in health spending [7]. Other analyses consistently document that obese individuals have a significantly higher use of health care services (including outpatient and inpatient visits) and associated costs (such as pharmacy costs) than nonobese patients [3, 6-19].

Not only does obesity place a significant burden on our health care system, it also has an impact on the costs to employers due to lost productivity, absences, underperformance, and higher insurance premiums. Data from the Medical Expenditures Panel Survey (MEPS) for 2000-2004 
showed that absenteeism costs associated with obesity total $\$ 4.3$ billion annually in the USA [17]. Among a sample of municipal workers, after accounting for age, gender, race, smoking behavior, and educational attainment, BMI predicted both average annual health care costs and work absence hours [18]. Using data from 61 US employers' health plan members' claims experiences between January 2000 and December 2004 showed that diagnosed, nondrug medical expenses attributable to obesity accounted for $21.3 \%$ of lifestyle health risks (accidents/injuries, alcohol/substance use, high cholesterol, high blood pressure, obesity, poor prenatal care, lack of exercise, smoking, stress, and poor dental hygiene) and $2.8 \%$ of all medical costs for those aged 19 to 64 years. Interestingly, this data also indicated that up to age 64 years (particularly those aged 55 to 64 years), females' obesity costs markedly exceed males [19]. Among manufacturing employees, moderately or extremely obese workers $(\mathrm{BMI} \geq 35)$ experienced a $4.2 \%$ health-related loss in productivity, $1.2 \%$ more than all other employees, which equates to an additional \$506 annually in lost productivity per worker [20].

Finally, a 2007 study explored the relationship between BMI and number and types of workers' compensation claims, associated costs, and lost workdays among 11,728 health care and university employees. Results indicated a clear linear relationship between BMI and rate of claims. Employees in obesity class III (BMI $\geq 40)$ had 11.65 claims per 1,000 full time employees (FTEs), while recommended-weight employees had 5.80: lost workdays 183.73 per 100 FTEs for overweight versus 14.19 for recommended-weight employees; medical claims costs ( $\$ 51,091$ versus $\$ 7,503$ per 100 FTEs), and indemnity claims costs $(\$ 59,178$ versus $\$ 5,396$ per 100 FTEs). The claims most strongly affected by BMI were related to lower extremity, wrist or hand, and back; pain or inflammation, sprain or strain, and contusion or bruise [21].

These data strongly indicate that employers should explore workplace interventions to reduce these costs [22]. Reducing obesity (along with tobacco use and inactivity) should be a priority for employers seeking to lower the incidence and severity of chronic illness and the associated demand for health services. Awareness of the costs associated with obesity among employees can stimulate employers to make the investment in providing employer-sponsored wellness and health improvement programs to address obesity [23]. The primary objective of this analysis is to examine the costs associated with obesity in an employee population and factors associated with increased costs.

\section{Materials and Methods}

The Physical Activity and Life Style (PALS) study was conducted at Emory University in Atlanta, Georgia, that employs over 12,000 staff and faculty [24]. The PALS study used a randomized prospective design to evaluate three interventions to increase physical activity among Emory employees. The analysis described in this paper utilized data (e.g., height and weight) from the baseline survey conducted for the main PALS study and linked this information with administrative data to determine health care costs.
2.1. Study Population. The PALS study population includes departments with at least six nonexempt (i.e., clock in and out for work each day) employees. Departments were excluded if the majority were employed by Emory University's Hospital system or if the primary location for the department was not on the university's main campus.

Individual employees were excluded for the following factors that precluded the need for an intervention, interfered with receiving the intervention, or interfered with conducting in-person interviews: (1) reported meeting CDC guidelines for physical activity, as assessed with a brief exercise screener; (2) worked nights; (3) worked off campus; (4) expected to be absent from work for more than a month in the next year (e.g., maternity leave, sabbatical); or (5) worked less than 20 hours/week. Faculty members and employees defined as exempt (i.e., not clocking in and out for work) were excluded because of their flexible work schedule.

Additional details about how departments and individuals were contacted to participate in PALS are provided elsewhere [24]. If determined eligible and willing, PALS participants were scheduled to have five data collection points over 9 months. This study used data from the baseline surveys conducted between April 2006 and March 2007: (1) Baseline Part A (demographics, health attitudes and behaviors, and work environment), on-line or on paper, and (2) Baseline Part B (physical activity recall, height and weight, and health literacy), in-person. The study protocol received approval from the Emory Institutional Review board.

2.2. Measures. The primary exposure variable was obesity (BMI $\geq 30)$. Height and weight measures were taken of participants by trained interviewers during the in-person baseline and nine-month follow-up surveys. The interviewers followed standard protocol used by the National Health and Nutrition Examination Survey for measuring height and weight [25]. Other covariates in this analysis were obtained from the baseline survey and included gender, race, age, income, education, marital status, job classification, health literacy skills, health-related behaviors (smoking status, gym membership, and attendance), self-reported health status, and physical and mental health (the number of unhealthy days in the past 30 days and the number of chronic conditions).

Claims data for all medical and pharmaceutical expenses were provided by Aetna, Blue Cross Blue Shield (BCBS), Medco, Towers Perrin, and United Behavior Science (UBH) for the period spanning May 2005 to February 2008 (34month period). The overwhelming majority (74\%) of employees were enrolled in the Aetna Point of Service plan, and plan choice did not vary by weight status (BMI) of study participants. Furthermore, all employees had the same prescription drug coverage plan. We created measures of average monthly costs for the following medical costs: total medical expenses, pharmaceutical expenses, inpatient expenses, and noninpatient expenses including physician visit, outpatient, emergency room, and other expenses. Pharmaceutical expenses are measured based on claims from Medco and Towers Perrin. Inpatient and noninpatient expenses are measured based on claims from Aetna, BCBS, and UBH. 
Total medical expenses then are obtained by aggregating pharmaceutical, inpatient, and noninpatient expenses. We also create measures of inpatient and noninpatient expenses for conditions related to obesity. We define obesity-related conditions using the claims-included primary ICD-9 codes related to visits for obesity (V65.3, V65.41, V69.0, V69.1, V77.8, V85.3, 278.00, 278.01, and 278.8), or related to diabetes, hypertension, coronary heart disease, and hyperlipidemia. We also created measures of average monthly out-of-pocket costs that are defined as the aggregate of copayments, coinsurance, and deductibles during this period for all medical expenses. Finally, we created average monthly sick leave hours obtained from the Emory University human resources records for the period spanning May 2005 to February 2008 (34-month period).

2.3. Analysis. We calculated the characteristics of the study population separately for nonobese (BMI $<30)$, obese (BMI $\geq 30$ ), and morbidly obese (BMI $\geq 35$ ) individuals. We also calculated the mean monthly medical expenses for each category of expenditures (total, pharmaceutical, inpatient, noninpatient, obesity-related inpatient, and obesity-related noninpatient expenses) for each weight category, the percent of individuals with positive expenses during any month of the 34-month period, and the mean monthly expenses for individuals with positive expenses. We initially examined whether the expenses for nonobese individuals are equivalent to those for obese individuals and whether the expenses for nonobese individuals are equivalent to those for morbidly obese individuals using $t$-tests. A $P$ value of 0.05 was used to determine statistical significance.

We also examined the relationship between medical expenses and obesity, conditional on individual demographics and health-related behaviors, using multivariate regression analysis. We estimated the probability that an individual has positive medical expenses for each category of expenditures using a logit model. We calculated average partial effects and heteroskedasticity-robust standard errors. Finally, we estimate a two-part regression model to account for the nonpositive expenditures and the right skewed distribution of medical expenditures, where the first part consists of a logit model predicting the probability of positive expenditures and the second part consists of a generalized linear model with a log link and a gamma distribution for individuals with positive expenditures. Bootstrapped standard errors are calculated with 400 replications. Two sets of covariates are used for all regressions. The first set of covariates includes sex, race (white, black, and other), marital status (married, single, and other), and age. The second set of covariates includes health behaviors and chronic conditions as defined above to examine whether the relationship between obesity and medical expenses is mediated by poor health behaviors and chronic conditions. Additional covariates denoting the treatment group that the individual was assigned to in the PALS study had no impact on the estimates of the relationship between obesity and medical expenses and thus are excluded from the results described below.

The average monthly sick leave hours used is positive for almost all individuals in the sample. Thus, we examined the relationship between obesity and average monthly sick leave hours using ordinary least squares regression models. We control for the same two sets of covariates as used in the models of medical expenditures.

\section{Results}

Unless otherwise noted, all results mentioned are statistically significant at $P<0.05$. Table 1 displays the differences in demographics and health behaviors of nonobese, obese, and morbidly obese individuals. In this sample, obese individuals are more likely to be black, are less likely to have completed college or graduate school, are less likely to attend a gym at least once a week, are more likely to report their health as fair or poor, have more unhealthy days in the past month, and have more chronic conditions than nonobese individuals. Morbidly obese individuals are more likely to be female, more likely to be black, are less likely to have completed college or graduate school, are less likely to attend a gym at least once a week, are more likely to report their health as fair or poor, have more unhealthy days in the past month, and have more chronic conditions than nonobese individuals. All other variables included in this analysis were not significantly different between obese or morbidly obese and nonobese individuals.

Table 2 demonstrates that the monthly average of all medical expenditures is $\$ 75$ more per month ( $\$ 905$ annually) for obese individuals than nonobese individuals and is $\$ 83$ more per month (\$992 annually) for morbidly obese individuals than nonobese individuals. These differences are not due to differences in whether these groups of individuals have any expenditures, since nearly all individuals have out-ofpocket expenses at least once during this 34-month period. Of the total medical expenditures, the monthly average of out-of-pocket expenditures is only $\$ 12$ more per month ( $\$ 138$ annually) for obese individuals than nonobese individuals and is only $\$ 17$ more per month ( $\$ 209$ annually) for morbidly obese individuals than nonobese individuals.

The largest differences in types of expenditures are differences in pharmaceutical expenses, with obese individuals spending \$34 and morbidly obese individuals spending $\$ 43$ more per month than nonobese individuals. Again, the differences in pharmaceutical expenses are not due to differences in the percent of each group having an expense. Although the average inpatient and noninpatient expenses of obese individuals are higher than nonobese individuals, these differences are not statistically significant. The average monthly inpatient expenses for all causes and causes related to obesity are small in magnitude; thus, we do not focus on these categories in the remaining tables. The average noninpatient expenses from causes related to obesity are higher among obese and morbidly individuals, compared to nonobese individuals, which reflects the differences in incurring this type of expense.

The mean differences in Table 2 could reflect the demographic differences between obese and nonobese individuals shown in Table 1. Table 3 displays the results of the twopart models that condition on demographics and models that also condition on socioeconomic characteristics, health 
TABLE 1: Characteristics of study population (means or $\%\{$ standard errors $\}$ ) by obesity status.

\begin{tabular}{|c|c|c|c|c|c|}
\hline & $\begin{array}{l}\text { Nonobese } \\
(\mathrm{BMI}<30)\end{array}$ & $\begin{array}{c}\text { Obese } \\
(\mathrm{BMI} \geq 30) \\
\end{array}$ & $\begin{array}{c}P \text { value } \\
\text { (nonobese }=\text { obese) }\end{array}$ & $\begin{array}{c}\text { Morbidly obese } \\
(\mathrm{BMI} \geq 35)\end{array}$ & $\begin{array}{c}P \text { value } \\
\text { (morbidly obese }=\text { nonobese) }\end{array}$ \\
\hline Number of observations & 255 & 199 & & 96 & \\
\hline Female & $60.8 \%(0.031)$ & $62.8 \%(0.034)$ & 0.659 & $74.0 \%(0.045)$ & 0.022 \\
\hline \multicolumn{6}{|l|}{ Race } \\
\hline White & $42.7 \%(0.031)$ & $36.7 \%(0.034)$ & 0.191 & $31.3 \%(0.047)$ & 0.050 \\
\hline Black & $45.5 \%(0.031)$ & $59.8 \%(0.035)$ & 0.003 & $65.6 \%(0.048)$ & 0.001 \\
\hline Other & $11.8 \%(0.020)$ & $4.0 \%(0.014)$ & 0.003 & $3.1 \%(0.018)$ & 0.013 \\
\hline Age & $41.3(0.7)$ & $43.4(0.7)$ & 0.057 & $43.2(1.0)$ & 0.166 \\
\hline Income & $\$ 49,235(1694.7)$ & $\$ 48,982(1823.0)$ & 0.919 & $\$ 48,437(2581.5)$ & 0.802 \\
\hline \multicolumn{6}{|l|}{ Educational status } \\
\hline High school & $16.1 \%(0.023)$ & $15.6 \%(0.026)$ & 0.885 & $13.4 \%(0.035)$ & 0.534 \\
\hline Some college & $32.9 \%(0.029)$ & $50.8 \%(0.035)$ & 0.000 & $56.7 \%(0.050)$ & 0.000 \\
\hline College & $33.7 \%(0.030)$ & $23.1 \%(0.030)$ & 0.014 & $20.6 \%(0.041)$ & 0.017 \\
\hline Masters & $16.1 \%(0.023)$ & $8.0 \%(0.019)$ & 0.010 & $6.2 \%(0.024)$ & 0.015 \\
\hline \multicolumn{6}{|l|}{ Marital status } \\
\hline Married & $47.1 \%(0.031)$ & $47.7 \%(0.035)$ & 0.885 & $44.8 \%(0.051)$ & 0.704 \\
\hline Single, never married & $31.4 \%(0.029)$ & $27.1 \%(0.032)$ & 0.326 & $32.3 \%(0.048)$ & 0.869 \\
\hline Other & $21.6 \%(0.026)$ & $25.1 \%(0.031)$ & 0.373 & $22.9 \%(0.043)$ & 0.786 \\
\hline \multicolumn{6}{|l|}{ Job classification } \\
\hline Facility management & $22.7 \%(0.026)$ & $25.1 \%(0.031)$ & 0.404 & $27.8 \%(0.045)$ & 0.319 \\
\hline Non-FM & $77.3 \%(0.026)$ & $73.9 \%(0.031)$ & 0.404 & $72.2 \%(0.047)$ & 0.319 \\
\hline $\begin{array}{l}\text { Adequate or above Health } \\
\text { literacy skills }\end{array}$ & $50.6 \%(0.031)$ & $54.3 \%(0.035)$ & 0.436 & $53.1 \%(0.051)$ & 0.672 \\
\hline Current smoker & $13.3 \%(0.021)$ & $8.5 \%(0.020)$ & 0.109 & $12.5 \%(0.034)$ & 0.834 \\
\hline Gym membership & $22.4 \%(0.026)$ & $23.1 \%(0.030)$ & 0.847 & $21.9 \%(0.042)$ & 0.924 \\
\hline $\begin{array}{l}\text { Gym attendance once a } \\
\text { week or more }\end{array}$ & $18.8 \%(0.024)$ & $10.1 \%(0.022)$ & 0.009 & $6.3 \%(0.025)$ & 0.004 \\
\hline Fair or poor health Status & $14.5 \%(0.022)$ & $31.7 \%(0.033)$ & 0.000 & $40.6 \%(0.050)$ & 0.000 \\
\hline Unhealthy days $^{\mathrm{a}}$ & $4.9(0.38)$ & $6.3(0.595)$ & 0.037 & $7.7(0.980)$ & 0.001 \\
\hline $\begin{array}{l}\text { Number of chronic } \\
\text { conditions }\end{array}$ & $0.47(0.050)$ & $0.86(0.067)$ & 0.000 & $0.96(0.104)$ & 0.000 \\
\hline
\end{tabular}

${ }^{a}$ Unhealthy days is measured as the number of days during the past 30 days when either physical or mental health was not good.

behaviors, and chronic conditions. As shown in column (1), total medical expenses for obese individuals are $\$ 81.7$ higher per month than nonobese individuals. As stated above, this result is driven by pharmaceutical expenses; obese individuals have pharmaceutical expenses that are \$38.6 higher per month than nonobese individuals, as shown in column (3). Additionally, obese related noninpatient expenses are $\$ 12.8$ higher per month, as shown in column (7), and total outof-pocket expenses are \$13.4 higher per month, as shown in column (9) for obese individuals than nonobese individuals. However, as shown in the even columns, socioeconomic characteristics, health behaviors, and chronic conditions mediate the relationship between obesity and medical expenses. As shown in column (4), controlling for these behaviors reduces the estimate for total medical expenditures to $\$ 52.2$ and it is no longer statistically significant. Further analyses suggest that obese individuals are more likely to have chronic conditions, which largely explains the decrease in the estimate from column (1) to column (2). Controlling for these variables also substantially decreases the estimates for pharmaceutical expenses and total out-of-pocket expenses. There are no statistically significant differences in inpatient or noninpatient expenditures.

Estimates of the relationship between obesity and average monthly sick leave hours taken are shown in Table 4. As shown in column (1), obese individuals use 1.44 more hours of sick leave per month than nonobese individuals. Controlling for socioeconomic status, health behaviors, and health status reduces the estimate to 1.03 more hours of sick leave per month, which remains statistically significant.

\section{Discussion}

Overall, our results in a population of university employees indicated that total medical expenditures were higher for obese individuals than nonobese individuals, which reflect 
TABLE 2: Health care expenses of study population (means or $\%$ \{standard errors $\}$ ) by obesity status.

\begin{tabular}{|c|c|c|c|c|c|}
\hline & $\begin{array}{l}\text { Nonobese } \\
(\mathrm{BMI}<30)\end{array}$ & $\begin{array}{c}\text { Obese } \\
(\mathrm{BMI} \geq 30)\end{array}$ & $\begin{array}{c}P \text { value } \\
\text { (obese }= \\
\text { nonobese) }\end{array}$ & $\begin{array}{c}\text { Morbidly } \\
\text { obese } \\
(\mathrm{BMI} \geq 35)\end{array}$ & $\begin{array}{c}P \text { value } \\
\text { (morbidly obese }= \\
\text { nonobese) }\end{array}$ \\
\hline Number of observations & 255 & 199 & & 96 & \\
\hline \multicolumn{6}{|c|}{ Total medical expenses } \\
\hline Monthly average costs & $180.1(17.8)$ & $255.5(28.4)$ & 0.020 & $262.8(35.8)$ & 0.024 \\
\hline $\begin{array}{l}\text { Percent of individuals with total costs } \\
>0\end{array}$ & $86.7 \%(0.021)$ & $86.4 \%(0.024)$ & 0.942 & $89.6 \%(0.031)$ & 0.463 \\
\hline Monthly average costs if costs $>0$ & $208.7(20.0)$ & $308.1(32.8)$ & 0.007 & $296.7(38.9)$ & 0.030 \\
\hline $\begin{array}{l}\text { Monthly average Total out-of-pocket } \\
\text { medical costs }\end{array}$ & $31.3(2.80)$ & $42.8(4.34)$ & 0.021 & $48.7(7.11)$ & 0.006 \\
\hline \multicolumn{6}{|c|}{ Pharmaceutical expenses } \\
\hline Monthly average costs & $39.0(7.24)$ & $73.0(12.4)$ & 0.013 & $82.3(18.9)$ & 0.009 \\
\hline $\begin{array}{l}\text { Percent of individuals with total costs } \\
>0\end{array}$ & $73.3 \%(0.028)$ & $77.4 \%(0.030)$ & 0.323 & $80.2 \%(0.041)$ & 0.185 \\
\hline Monthly average costs if costs $>0$ & $58.4(10.6)$ & $100.9(16.5)$ & 0.026 & $105.3(23.6)$ & 0.037 \\
\hline \multicolumn{6}{|c|}{ Inpatient expenses } \\
\hline Monthly average costs & $19.2(7.63)$ & $29.1(7.70)$ & 0.370 & $22.3(7.21)$ & 0.815 \\
\hline $\begin{array}{l}\text { Percent of individuals with total costs } \\
>0\end{array}$ & $7.8 \%(0.017)$ & $16.1 \%(0.026)$ & 0.006 & $16.7 \%(0.038)$ & 0.015 \\
\hline Monthly average costs if costs $>0$ & $272.3(91.0)$ & $214.3(42.5)$ & 0.525 & $164.7(32.9)$ & 0.341 \\
\hline \multicolumn{6}{|c|}{ Noninpatient expenses } \\
\hline Monthly average costs & $121.9(11.8)$ & $153.3(18.1)$ & 0.132 & $158.2(22.5)$ & 0.127 \\
\hline $\begin{array}{l}\text { Percent of individuals with total costs } \\
>0\end{array}$ & $83.5 \%(0.023)$ & $80.9 \%(0.028)$ & 0.468 & $85.4 \%(0.036)$ & 0.668 \\
\hline Monthly average costs if costs $>0$ & $145.9(13.5)$ & $193.1(21.8)$ & 0.055 & $185.2(25.2)$ & 0.145 \\
\hline \multicolumn{6}{|c|}{ Obese related inpatient expenses } \\
\hline Monthly average costs & $6.31(6.22)$ & $6.32(3.06)$ & 0.999 & $2.39(2.17)$ & 0.702 \\
\hline $\begin{array}{l}\text { Percent of individuals with total costs } \\
>0\end{array}$ & $1.18 \%(0.007)$ & $5.53 \%(0.016)$ & 0.008 & $5.21 \%(0.023)$ & 0.024 \\
\hline Monthly average costs if costs $>0$ & $536.7(524.4)$ & $114.3(46.1)$ & 0.128 & $45.9(40.6)$ & 0.252 \\
\hline \multicolumn{6}{|c|}{ Obese related noninpatient expenses } \\
\hline Monthly average costs & $8.20(2.32)$ & $20.9(4.50)$ & 0.008 & $25.3(8.16)$ & 0.007 \\
\hline $\begin{array}{l}\text { Percent of individuals with total costs } \\
>0\end{array}$ & $29.0 \%(0.028)$ & $49.2 \%(0.036)$ & 0.000 & $54.2 \%(0.051)$ & 0.000 \\
\hline Monthly average costs if costs $>0$ & $29.8(7.94)$ & $42.8(8.72)$ & 0.291 & $46.6(14.5)$ & 0.280 \\
\hline
\end{tabular}

TABLE 3: The relationship between obesity and average monthly medical expenses (two-part model estimates) $(N=454)$.

\begin{tabular}{|c|c|c|c|c|c|c|c|c|c|c|}
\hline & \multicolumn{2}{|c|}{$\begin{array}{l}\text { Total medical } \\
\text { expenses }\end{array}$} & \multicolumn{2}{|c|}{$\begin{array}{l}\text { Pharmaceutical } \\
\text { expenses }\end{array}$} & \multicolumn{2}{|c|}{$\begin{array}{l}\text { Noninpatient } \\
\text { expenses }\end{array}$} & \multicolumn{2}{|c|}{$\begin{array}{c}\text { Obese related } \\
\text { noninpatient } \\
\text { expenses }\end{array}$} & \multicolumn{2}{|c|}{$\begin{array}{l}\text { Total } \\
\text { out-of-pocket } \\
\text { medical expenses }\end{array}$} \\
\hline & (1) & (2) & (3) & (4) & (5) & (6) & (7) & $(8)$ & (9) & $(10)$ \\
\hline \multirow[t]{2}{*}{ Obese } & $81.7^{* *}$ & 52.2 & $38.6^{* *}$ & 16.3 & 32.3 & 15.6 & $12.8^{* *}$ & $12.7^{* *}$ & $13.44^{* *}$ & 8.09 \\
\hline & $(36.3)$ & (35.1) & $(16.7)$ & (13.8) & (21.9) & $(21.7)$ & (5.3) & (5.8) & (6.11) & (5.73) \\
\hline
\end{tabular}

Notes: heteroskedasticity-robust standard errors in parentheses. Two-part model estimates are estimated using a logit model in the first part and a generalized linear model with a log link and a gamma distribution for the second part. Covariates in the odd-numbered columns include gender, race, marital status, and age. Covariates in the even-numbered columns also include socioeconomic characteristics (education, income, and occupation category), health behaviors (smoking status, gym membership and attendance, health literacy, and health status), and the number of chronic conditions.

${ }^{*} P<0.1,{ }^{* *} P<0.05$, and ${ }^{* * *} P<0.01$. 
TABLE 4: The relationship between obesity and average monthly sick leave hours $(N=424)$.

\begin{tabular}{lcc}
\hline & \multicolumn{2}{c}{ Monthly sick leave hours } \\
Models & $(1)$ & $(2)$ \\
\hline Obese & $1.44^{* * *}$ & $1.03^{* *}$ \\
& $(0.38)$ & $(0.44)$ \\
\hline
\end{tabular}

Notes: heteroskedasticity-robust standard errors in parentheses. The covariates included but not shown are the same as the covariates included in Table 3.

${ }^{* *} P<0.05$, and ${ }^{* * *} P<0.01$.

the poorer health behaviors and health status of obese adults. The differences in total medical expenditures were primarily due to higher pharmaceutical expenses, as being obese is not predictive of higher inpatient or outpatient expenses. Further, being obese increased the probability of having noninpatient expenses for obesity related medical conditions but did not increase the amount of noninpatient expenses for these conditions. Additionally, obese individuals had higher out-of-pocket expenses, but these expenses were small in magnitude and also reflected the poorer health behaviors and health status of obese adults.

This study has at least five strengths. First, cost data were available for three years. This time period is longer than most other studies that have examined costs using MEPS data or employer costs associated with obesity. Second, we had actual measurements of obesity, rather than most studies that have relied on self-reported height and weight data, which is important due to recent results that self-reported measures lead to underestimation of the relationship between obesity and medical costs [26]. Third, we had more recent cost data available compared to others that examined older data [27]. Fourth, we had additional information about study participants, including demographic characteristics and mental and physical health measures, which allowed us to examine whether the higher medical costs of obesity are due to obesity or the resulting comorbidities. Finally, results from this study had implications for worksite interventions by potentially motivating employers to provide programs for employees who are overweight/obese.

Despite the numerous strengths of this study, there are at least three limitations. First, the study population only included individuals covered by private health insurance plans. However, the majority of employed Americans are covered by private health plans. Therefore, this data is useful to specifically examine employer costs associated with obesity. Second, data were only available from employees who were covered by Emory health insurance plans. Employees who were covered by other plans (e.g., spouse coverage) were not included; however, $90.5 \%$ of Emory employees are covered by Emory health plans. Finally, the sample size is relatively small, although fairly similar to MEPS data.

Our results suggest that the additional total medical expenditures for obese employees are $\$ 905$ per year and for morbidly obese employees are $\$ 992$ per year. These differences are mostly driven by pharmaceutical expenses and are attributable to demographics, socioeconomic characteristics, health-related behaviors, and health status. In contrast, Finkelstein et al. find that the increase in medical spending due to obesity is $\$ 1140$ per year (2008 dollars) for privately insured individuals and that inpatient and noninpatient costs account for approximately three-fourths of the additional expenses [6]. Further, Cawley et al. find that obesity increases medical expenses by $\$ 4393$ per year (2005 dollars) for privately insured adults [17].

A difference between our results and previous results in the literature is that we are able to control for a wide array of individual characteristics and we find that the additional medical expenses reflect the health status of obese individuals as opposed to obesity causing an increase in medical expenditures. A second difference is that we focus on a sample of employees offered generous health insurance plans as a benefit of employment. Our results show that, provided with generous health insurance plans, the additional out-ofpocket expenditures by obese individuals are minimal. In contrast, the premiums for these health insurance plans have increased in recent years. For example, the full premium for the most generous insurance plan increased by $61 \%$ between 2004 and 2008 for family coverage, and employees paid only $1 \%$ of this increase. During this period, the deductible for services provided within the core network remained at $\$ 0$. The high additional medical expenditures attributable to obesity shown in the previous literature are not reflected in out-of-pocket expenditures for these employees because most expenses are covered under the available insurance plans and the additional costs due to obesity are incorporated into the health insurance premiums. Thus, the additional costs of obesity are only partially paid by obese employees through higher premiums and these health insurance plans redistribute costs from obese to nonobese employees who pay the same insurance premiums.

\section{Disclaimer}

The contents of the paper are solely the responsibility of the authors and do not necessarily represent the official views of CDC.

\section{Conflict of Interests}

The authors declare that there is no conflict of interests regarding the publication of this paper.

\section{Acknowledgments}

This paper was supported by CDC-R01 DP000107-03 from the Centers for Disease Control and Prevention. This research was partially supported by the Emory Global Health Institute through a Faculty Distinction Fund Award to Dr. Frisvold.

\section{References}

[1] A. H. Mokdad, M. K. Serdula, W. H. Dietz, B. A. Bowman, J. S. Marks, and J. P. Koplan, "The spread of the obesity epidemic in the United States, 1991-1998," Journal of the American Medical Association, vol. 282, no. 16, pp. 1519-1522, 1999. 
[2] C. L. Ogden, M. D. Carroll, B. K. Kit, and K. M. Flegal, "Prevalence of childhood and adult obesity in the United States, 2011-2012," Journal of the American Medical Association, vol. 311, no. 8, pp. 806-814, 2014.

[3] A. Must, J. Spadano, E. H. Coakley, A. E. Field, G. Colditz, and W. H. Dietz, "The disease burden associated with overweight and obesity," Journal of the American Medical Association, vol. 282, no. 16, pp. 1523-1529, 1999.

[4] C. Zhang, K. M. Rexrode, R. M. Van Dam, T. Y. Li, and F. B. Hu, "Abdominal obesity and the risk of all-cause, cardiovascular, and cancer mortality: 16 years of follow-up in US women," Circulation, vol. 117, no. 13, pp. 1658-1667, 2008.

[5] K. M. Flegal, B. K. Kit, H. Orpana, and B. I. Graubard, "Association of all-cause mortality with overweight and obesity using standard body mass index categories: a systematic review and meta-analysis," The Journal of the American Medical Association, vol. 309, no. 1, pp. 71-82, 2013.

[6] E. A. Finkelstein, I. C. Fiebelkorn, and G. Wang, "National medical spending attributable to overweight and obesity: how much, and who's paying?" Health Affairs, pp. w822-w831, 2009.

[7] K. E. Thorpe, C. S. Florence, D. H. Howard, and P. Joski, “The impact of obesity on rising medical spending," Health Affairs, pp. W4-480-W4-486, 2004.

[8] K. D. Bertakis and R. Azari, "Obesity and the use of health care services," Obesity Research, vol. 13, no. 2, pp. 372-379, 2005.

[9] P. Muennig, E. Lubetkin, H. Jia, and P. Franks, "Gender and the burden of disease attributable to obesity," The American Journal of Public Health, vol. 96, no. 9, pp. 1662-1668, 2006.

[10] E. Finkelstein, I. C. Fiebelkorn, and G. Wang, "The costs of obesity among full-time employees," The American Journal of Health Promotion, vol. 20, no. 1, pp. 45-51, 2005.

[11] L. H. Anderson, B. C. Martinson, A. L. Crain et al., "Health care charges associated with physical inactivity, overweight, and obesity," Prevention of Chronic Disease, vol. 2, no. 4, article A09, 2005.

[12] D. E. Arterburn, M. L. Maciejewski, and J. Tsevat, "Impact of morbid obesity on medical expenditures in adults," International Journal of Obesity, vol. 29, no. 3, pp. 334-339, 2005.

[13] C. C. Wee, R. S. Phillips, A. T. R. Legedza et al., "Health care expenditures associated with overweight and obesity among us adults: importance of age and race," American Journal of Public Health, vol. 95, no. 1, pp. 159-165, 2005.

[14] G. Oster, J. Edelsberg, A. K. O'Sullivan, and D. Thompson, “The clinical and economic burden of obesity in a managed care setting," The American Journal of Managed Care, vol. 6, no. 6, pp. 681-689, 2000.

[15] R. Sturm, "The effects of obesity, smoking, and drinking on medical problems and costs," Health Affairs, vol. 21, no. 2, pp. 245-253, 2002.

[16] Z. Yang and A. G. Hall, "The financial burden of overweight and obesity among elderly Americans: the dynamics of weight, longevity, and health care cost," Health Services Research, vol. 43, no. 3, pp. 849-868, 2008.

[17] J. Cawley, J. A. Rizzo, and K. Haas, "Occupation-specific absenteeism costs associated with obesity and morbid obesity," Journal of Occupational \& Environmental Medicine, vol. 49, no. 12, pp. 1317-1324, 2007.

[18] T. Bungum, M. Satterwhite, A. W. Jackson, and J. R. Morrow Jr., "The relationship of body mass index, medical costs, and job absenteeism," The American Journal of Health Behavior, vol. 27, no. 4, pp. 456-462, 2003.
[19] D. A. Long, R. Reed, and G. Lehman, "The cost of lifestyle health risks: obesity," Journal of Occupational and Environmental Medicine, vol. 48, no. 3, pp. 244-251, 2006.

[20] D. M. Gates, P. Succop, B. J. Brehm, G. L. Gillespie, and B. D. Sommers, "Obesity and presenteeism: the impact of body mass index on workplace productivity," Journal of Occupational and Environmental Medicine, vol. 50, no. 1, pp. 39-45, 2008.

[21] T. Østbye, J. M. Dement, and K. M. Krause, "Obesity and workers' compensation: results from the duke health and safety surveillance system," Archives of Internal Medicine, vol. 167, no. 8, pp. 766-773, 2007.

[22] J. Cawley, J. A. Rizzo, and K. Haas, "Occupation-specific absenteeism costs associated with obesity and morbid obesity," The American Journal of Health Behavior, vol. 49, no. 12, pp. 1317-1324, 2007.

[23] L. Heinen and H. Darling, "Addressing obesity in the workplace: the role of employers," Milbank Quarterly, vol. 87, no. 1, pp. 101$122,2009$.

[24] J. A. Gazmararian, L. Elon, K. Newsome, L. Schild, and K. L. Jacobson, "A randomized prospective trial of a worksite intervention program to increase physical activity," American Journal of Health Promotion, vol. 28, no. 1, pp. 32-40, 2013.

[25] Centers for Disease Control and Prevention and National Center for Health Statistics, National Health and Nutrition Examination Survey, May 2012, http://www.cdc.gov/nchs/nhanes/ nhanes_questionnaires.htm.

[26] J. Cawley and C. Meyerhoefer, "The medical care costs of obesity: an instrumental variables approach," Journal of Health Economics, vol. 31, no. 1, pp. 219-230, 2012.

[27] E. A. Finkelstein, J. G. Trogdon, J. W. Cohen, and W. Dietz, "Annual medical spending attributable to obesity: payer-and service-specific estimates," Health Affairs, vol. 28, no. 5, pp. w822-w831, 2009. 


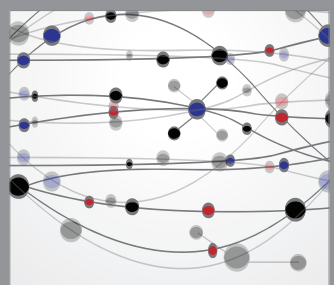

The Scientific World Journal
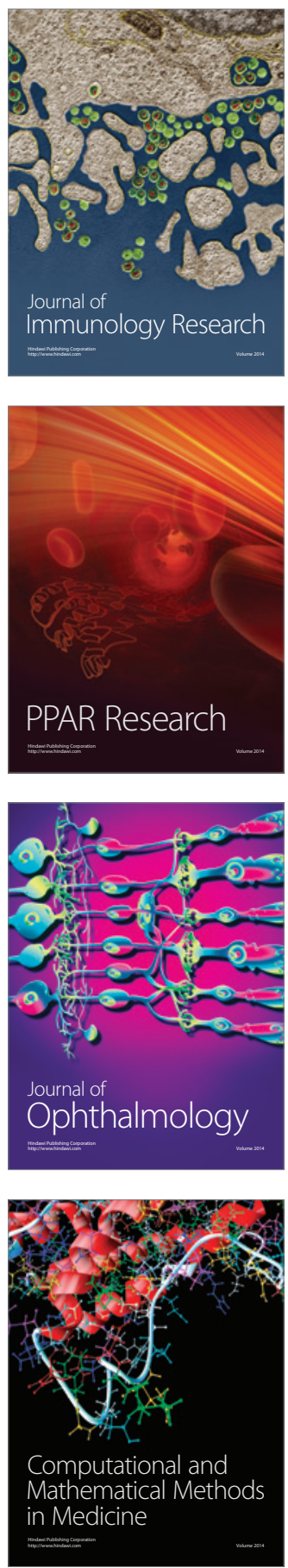

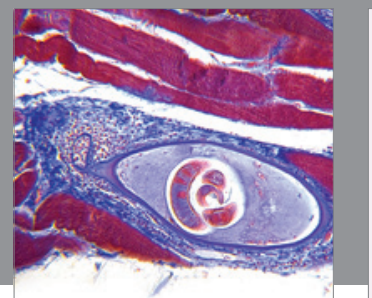

Gastroenterology

Research and Practice
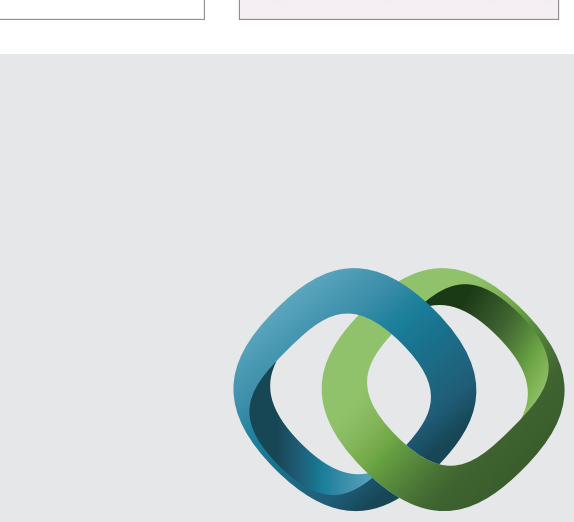

\section{Hindawi}

Submit your manuscripts at

http://www.hindawi.com
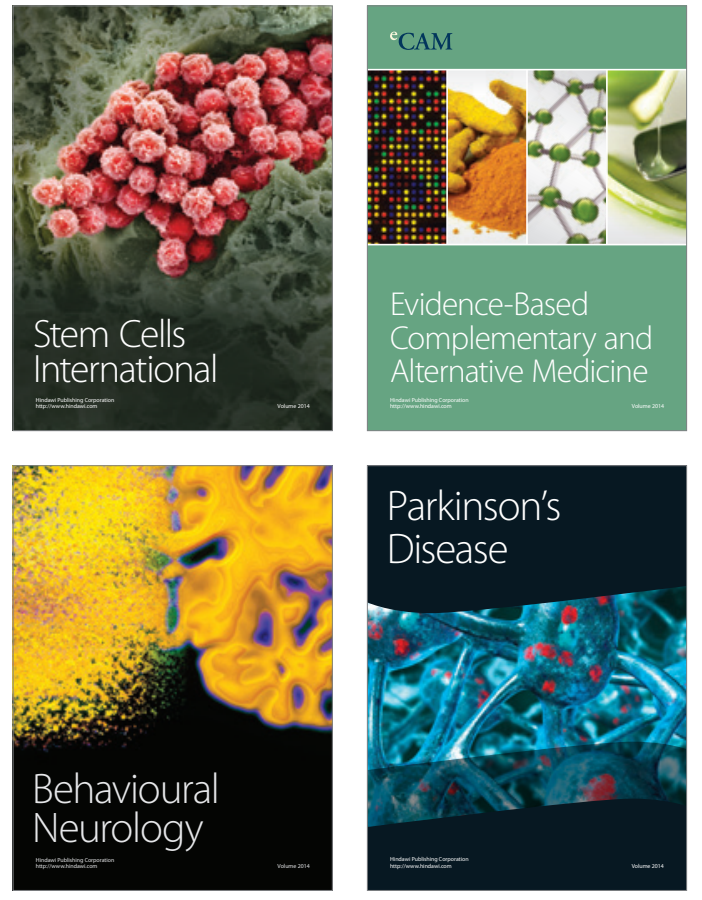
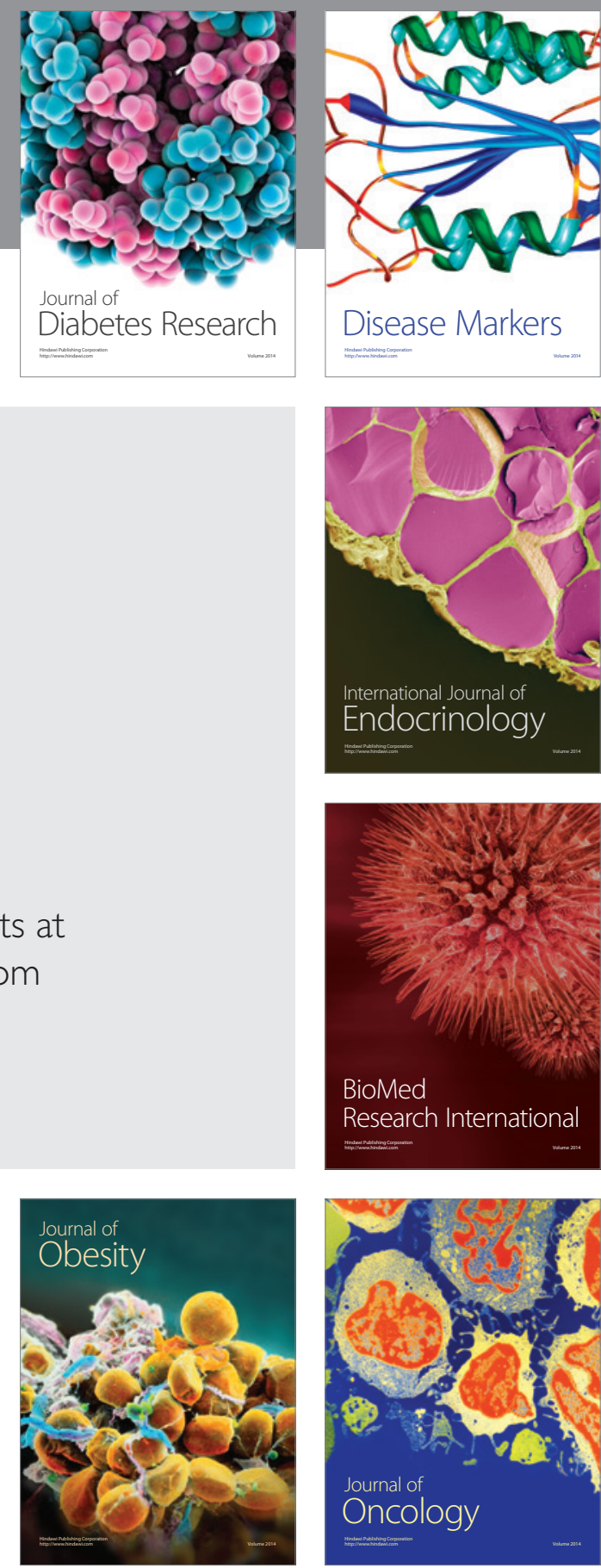

Disease Markers
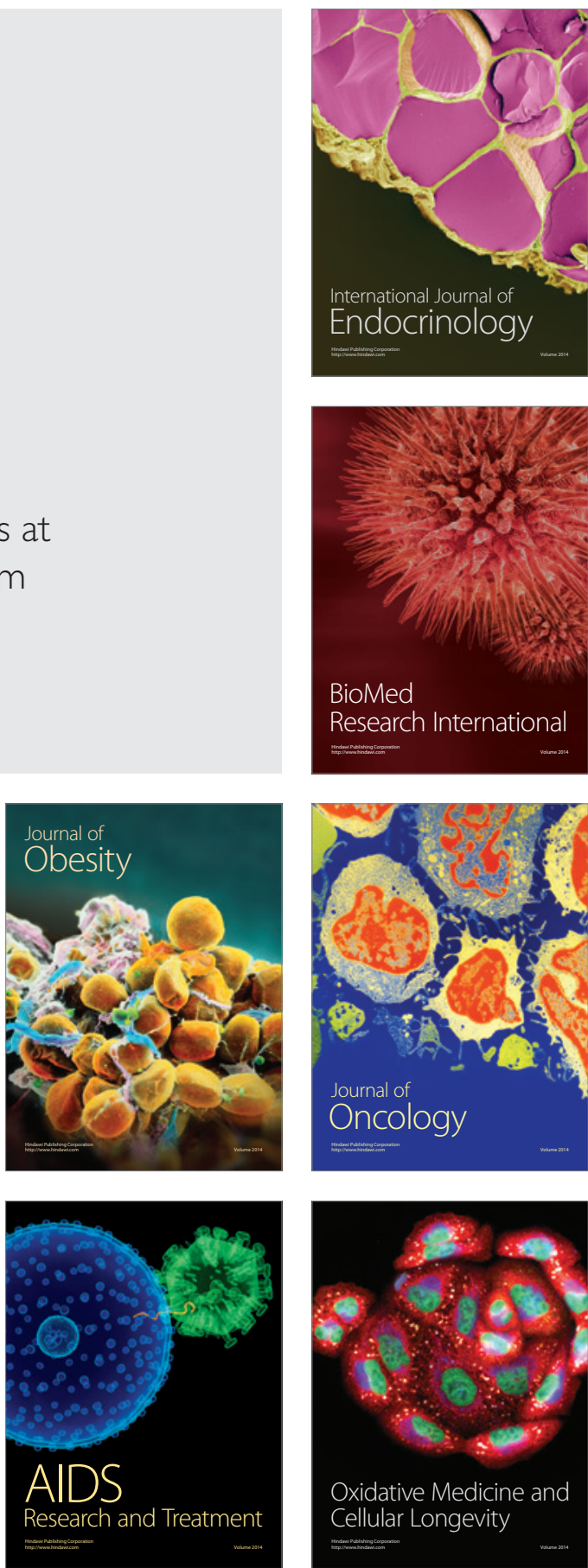